\title{
Management Buy-out Pricing Model: A Fairness Preference Perspective
}

\author{
Chuan Liu*
}

Business school of Central South University, Changsha, Hunan, 410083, China

\begin{abstract}
In order to determine the effective and reasonable management buyout price, considered of asymmetric information, this paper investigated the shareholders' decision-making behavior during the management buyout pricing process under a fairness preferences perspective. The conclusions in this paper were: 1) The greater the value of the option, the smaller the critical probability of management buy-out success, namely smaller posteriori probability of the original shareholders to the management; and 2) MBO share is affected by inequity aversion. In order to enhance utility, management with higher degree of inequity aversion would increase the probability of cheating and moral hazard. The contributions of this paper were: the signal display principle of option value has been found; and studied the fairness preference during the process, psychological disutility produced by fairness preference has a crowding-out effect on managerial ownership's incentive contracts.
\end{abstract}

Keywords: Fairness preference, management buy-outs, game.

\section{INTRODUCTION}

Principal-agent theory based on self-interest assumption deems that management buyout (MBO) could clarify property rights, motivate the management and achieve equilibrium among managers and shareholders. During the transitional period in China, however, MBO gives rise to illegal operations, unreasonable pricing and erosion of state assets owing to the imperfection of related laws and market regulations. This problem mainly arises from the unfairness of MBO pricing process, causing the controversy about MBO pricing aiming at target enterprise among the related parties. The MBO program could hardly get recognition by society when corporate owners consider that the target enterprise pricing reflects the unfair and unreasonable allocation of enterprise value-added income, even cannot compensate the absorption cost. In the special development stage of emerging markets and transformation of society, the significance and urgency of MBO pricing reform are increasingly prominent. Whether handling this problem effectively or not, is not only primarily concerned with the success of state-ownedenterprises reform, but also lays a solid foundation for the stable development of society and economy.

For the purpose of fixing MBO price accurately and reasonably, it is in urgent need of breaking deficiently competitive market price stemming from the one-to-one bilateral monopoly of $\mathrm{MBO}$ and exclusive pricing agreement due to the advantage of multi-information of operating gained by management [1]. Although the gradual perfection of takeover market improves the MBO pricing method, which has great influences on large shareholders by management buyout price formation mechanism on secondary market, and conference pricing turns internal game between shareholders into market game and tends to be rational gradually, the definition of MBO pricing is still not clear. There are many factors affecting MBO price other than systematic arbitrage, such as uncertainty and psychological preferences. Therefore, constructing the option game behavior analysis framework which integrates option value and psychological effect becomes a key to MBO decision theoretical breakthrough.

The method of behavioral option game adopts unified analysis framework for project evaluation and decision to overcome the limitations of traditional management decision-making method, including uncertainty, irreversibility and competitiveness faced by $\mathrm{MBO}$, the interaction between stakeholders and the psychological effect produced by gameagent in the process of the acquisition. Therefore, Ziegler [2], pointed out that the project decision analysis under the option games analyzed the value of uncertainty and the flexible investment decisions under uncertainty ignored by standard game theory analysis paradigm, and figured out the problem of real options in dealing with competition endogeneity, thus the rule of expected utility maximization in agent analysis paradigm developed into the expected utility maximization embedded option value. Option game project decision-making model includes continuous time option game model $[3,4]$, discrete time option game model $[5,6]$, the combination of discrete and continuous time options game model expressed by binomial $[7,8]$ and MBO model of decision-making behavior containing the options value [9-14]. All of these research results highlight the intrinsic meaning of MBO based on the behavior of option game. Moreover, game experiments carried out recently demonstrate the existence of fairness preference ignored by the traditional agency theory, including ultimatum game, dictator games, gift exchange game, public goods game and trust game, which affect MBO decision-making behavior through utility function. The model includes interactive fair equilibrium model (Rabin [13]), modified sequential reciprocity equilibrium 
model (Dufwenberg \& Kirchsteiger [14]), modified reciprocal fairness equilibrium model (Falk \& Fischbacher [15]) and fair equilibrium model based on allocation result (Fehr \& Schmidt[16],Bolton \& Ockenfels [17]). The models mentioned above are analysis tools expanding the concrete form of the utility function, considering the various social preferences and based on the game theory.

Unlike literature mentioned above, this paper intends to analyze MBO decision-making behavior of shareholders and the management under the condition of asymmetric information from a new perspective. We are trying to add various options value to the acquired optimal decision-making process and construct an analysis framework implied the expected utility maximization of option value. Meanwhile, according to the developing principal-agent theory, we add some human social emotional factors to utility function, such as fairness and mutual benefit which are different from selfinterest. Given social preferences utility in decision-making, the rule of expected utility maximization in agent analysis paradigm develops into the expected utility maximization. As long as fairness faith is given to game related subjects, the value of target enterprise will not only be determined by cash flow, but also by social psychological effects.

\section{MODIFICATION TO ENTERPRISE VALUE AND UTILITY FUNCTION}

\subsection{Modification to Enterprise Value Made by Option Value}

In the process of $\mathrm{MBO}$, there exist two kinds of option values modifying target enterprise value. One is owing to enterprise future growth opportunities from M\&A, for example, delay option, that is to say, the management will take advantage of information superiority and delay the project under construction till the time is right if this project exerts negative influence on target enterprise. The other is due to the flexibility in the process-the improvement of control power, ownership structure and corporate governance give rise to control premium value, ownership structure premium value and corporate governance premium value. It is necessary to repair MBO organization on account of those option values so as to protect the interests of existing shareholders. The option value could be obtained by B-S option pricing model. Assuming net present value of target enterprise is $V$, MBO option value is the function $P(V, t)$ of Net Asset Value and time t. According to ITO lemma, we could find out:

$d P=\left(\frac{\partial P}{\partial V} u V+\frac{\partial P}{\partial t}+\frac{1}{2} \frac{\partial^{2} P}{\partial V^{2}} \sigma^{2} V^{2}\right) d t+\frac{\partial P}{\partial V} \sigma \sqrt{d t} \xi$

To gain MBO option value, we can take the following combination into consideration: selling option of assets, buying net assets of target Enterprise $\frac{\partial P}{\partial V} V$, so the value of combination is: $\Pi=-P+\frac{\partial P}{\partial V} V$, after $\Delta t$ time, the portfolio value is: $\Pi=-P+\frac{\partial P}{\partial V} \Delta V$, thus getting the following changes of portfolio value:
$\Delta \Pi=-\left(\frac{\partial P}{\partial t}+\frac{1}{2} \frac{\partial^{2} P}{\partial V^{2}} \sigma^{2} V^{2}\right) \Delta t$

According to no arbitrage principle, we can get: $\Delta \Pi=\Pi \cdot r \cdot \Delta t, r$ is risk-free interest rate, so there is an equation:

$\frac{\partial P}{\partial t}+r V \frac{\partial P}{\partial S}+\frac{1}{2} \frac{\partial^{2} P}{\partial V^{2}} \sigma^{2} V^{2}=r V$

MBO real options is parallel to European call, when $\mathrm{t}=\mathrm{T}$, the boundary conditions of $\mathrm{MBO}$ option is:

$P[V(T), T]=\operatorname{Max}[V(T)-K, 0]$

So we obtain the stochastic equations:

$\left\{\begin{array}{l}\frac{\partial P}{\partial t}+r V \frac{\partial P}{\partial S}+\frac{1}{2} \frac{\partial^{2} P}{\partial V^{2}} \sigma^{2} V^{2}=r V \\ P[V(t), t]=\operatorname{Max}[V(t)-K, 0]\end{array}\right.$

According to typical heat conduction equation, doing variable substitution like like $V=K e^{y}, \quad t=T-2 \frac{\tau}{\sigma^{2}}$, $P=K \cdot V(y, t)$, getting simplified stochastic equations:

$\left\{\begin{array}{l}\frac{\partial V}{\partial \tau}+\frac{2 r}{\sigma^{2}} V=\frac{\partial^{2} V}{\partial y^{2}}+\left(\frac{2 r}{\sigma^{2}}-1\right) \frac{\partial V}{\partial y} \\ V(y, 0)=\operatorname{Max}\left(e^{y}-1,0\right)\end{array}\right.$

Through further variable substitution, we can get:

$V(y, \tau)=\exp \left[\left(\frac{1}{2}-\frac{r}{\sigma^{2}}\right) y-\left(\frac{1}{2}+\frac{r}{\sigma^{2}}\right)^{2} \tau\right] U(y, t)$

Taking equation (7) into equation (6), we obtain stochastic equations:

$\left\{\begin{array}{l}\frac{\partial U}{\partial \tau}=\frac{\partial^{2} U}{\partial y^{2}} \\ U(y, 0)=\operatorname{Max}\left\{\exp \left[\left(\frac{1}{2}+\frac{r}{\sigma^{2}}\right) y\right]-\exp \left[\left(\frac{r}{\sigma^{2}}-\frac{1}{2}\right) y\right], 0\right\}\end{array}\right.$

$\frac{\partial U}{\partial \tau}=\frac{\partial^{2} U}{\partial v^{2}}$ is heat conduction equation, so the result is:

$U(y, \tau)=\frac{1}{2 \sqrt{\pi \tau}} \int_{-\infty}^{\infty} U(u, 0) \exp \left(-\frac{(y-u)^{2}}{4 \tau}\right) d u$

Taking

$U(y, 0)=\operatorname{Max}\left\{\exp \left[\left(\frac{1}{2}+\frac{r}{\sigma^{2}}\right) y\right]-\exp \left[\left(\frac{r}{\sigma^{2}}-\frac{1}{2}\right) y\right], 0\right\}$

into equation (7), we can get:

$$
\begin{aligned}
U(y, \tau) & =\frac{1}{2 \sqrt{\pi \tau}} \int_{0}^{\infty} \exp \left[\left(\frac{1}{2}+\frac{r}{\sigma^{2}}\right) u-\frac{(y-u)^{2}}{4 \tau}\right] d u \\
& -\frac{1}{2 \sqrt{\pi \tau}} \int_{0}^{\infty} \exp \left[\left(\frac{r}{\sigma^{2}}-\frac{1}{2}\right) u-\frac{(y-u)^{2}}{4 \tau}\right] d u
\end{aligned}
$$


The equation (10) is integrated as:

$$
\begin{aligned}
U(y, \tau) & =\exp \left[\left(\frac{1}{2}+\frac{r}{\sigma^{2}}\right) y+\left(\frac{1}{2}+\frac{r}{\sigma^{2}}\right)^{2} \tau\right] N\left(d_{1}\right) \\
& -\exp \left[\left(\frac{r}{\sigma^{2}}-\frac{1}{2}\right) y+\left(\frac{r}{\sigma^{2}}-\frac{1}{2}\right)^{2} \tau\right] N\left(d_{2}\right)
\end{aligned}
$$

And

$$
d_{1}=\frac{y}{\sqrt{2 \tau}}\left(\frac{1}{2}+\frac{r}{\sigma^{2}}\right) \sqrt{2 \tau} \quad d_{2}=\frac{y}{\sqrt{2 \tau}}\left(\frac{r}{\sigma^{2}}-\frac{1}{2}\right) \sqrt{2 \tau}
$$

Taking equation (11) into equation (7), we can get:

$V(y, \tau)=e^{y} N\left(d_{1}\right)-e^{-\frac{2 r \tau}{\sigma^{2}}} N\left(d_{2}\right)$

Combining equation (11) and equation (12), we can get the growth option value of $\mathrm{MBO}$ :

$$
P=(V, t)=V N\left(d_{1}\right)-K e^{-r(T-t)} N\left(d_{2}\right)
$$

And

$$
\begin{array}{r}
d_{1}=\frac{\left[\operatorname{In} \frac{V(t)}{K}+\left(r+\frac{1}{\sigma^{2}}\right)(T-t)\right]}{\sigma \sqrt{T-t}} \\
d_{2}=\frac{\left[\operatorname{In} \frac{V(t)}{K}+\left(r-\frac{1}{\sigma^{2}}\right)(T-t)\right]}{\sigma \sqrt{T-t}}
\end{array}
$$

Therefore, given all kinds of option values in $\mathrm{MBO}$, purchasing price of target enterprise should be no less than its net asset value $\mathrm{V}$, or it would result in the loss of stateowned assets and damages to the interests of existing shareholders. However, net asset value $\mathrm{V}$ of target enterprise should be no more than the summation of $\mathrm{V}$ and option value $\mathrm{P}$, otherwise it would decrease the motivation of $\mathrm{MBO}$ and it is impossible to share the premium value of control power, ownership structure and corporate governance generated by MBO. It can be seen from equation (13) that if MBO game price is regarded as options strike price, options strike price would affect option value, and option value would affect $\mathrm{MBO}$ game price in return.

\subsection{Modification and Crowding-out Effect to Manage- ment Utility Function Made by Fairness Preference}

During the MBO progress, the managers who are involved in tends to pay attention on the relative incomes. The comparison psychology preference for relative income is a kind of fairness preference confirmed by experimental game, neural economics and psychology, and prevalent in the decision-making process. This preference means that people not only care about their own income, but are concerned about the fairness of income distribution, and the unfair income distribution would have a negative effect on the preference. The existence of the negative utility would influence the strategy selection of the game subjects, resulting in the change of the game equilibrium of MBO.

When the fairness preference transforms into psychological utility, it would change the utility function for MBO de- cision. To specify form of utility function to the MBO decision, the Fehr \& Schmidt measurement is taken in this paper. Given that the enterprise overall value $v$ is a continuous ran-

dom variable, whose interval range is $v \in(\underline{v}, \bar{v})$, and the output of enterprise mainly depends on how hard the management works; therefore, the probability density function of

its output could be $f(v / e)$. The effort of management has a cost, and its effort cost function could be assumed to be $c=c(e)$. The function is an increasing function of $\mathrm{e}$, and $c^{\prime}(e)>0, c^{\prime \prime}(e)>0$, which means the harder the management works, the higher cost it has to pay, and with the increase of the degree of effort, management costs increase. The equity ratio of $\mathrm{MBO}$ is $\beta$, and the earnings of management is $\beta \mathrm{v}$, the difference between the income of business owners and the management is taken to measure the loss of utility caused by inequality aversion:

$\mathrm{E}($ Fairness Preference $)=\gamma G\{[v-\beta v]-\beta v\}$

$\gamma$ stands for the degree of inequality aversion. Since the management has more private information than the owners about enterprise value and individual efforts, the contract signed by shareholders and the management is incomplete. Thus the MBO principal agent decision-making model based on inequality aversion could be:

$$
\begin{aligned}
& \max _{\beta} \quad E U_{P}=\int_{\underline{v}}^{\bar{v}} f(v / e)[v-\beta v] d v \\
& \text { s.t.(PC) } E U_{A}=\int_{v}^{\bar{v}} f(v / e)[u(\beta v)-\gamma G\{[v-\beta v]-\beta v\}] d v \\
& -c(e) \geq \bar{U} \\
& \begin{array}{l}
\int_{\underline{v}}^{\bar{v}} f_{e}(v / e)[u(\beta v)-\gamma G\{[v-\beta v]-\beta v\}] d v-c^{\prime}(e) \\
\quad=0
\end{array}
\end{aligned}
$$

According to the behavioral principal-agent optimization first-order analysis method, a Lagrange function could be structured:

$$
\begin{aligned}
L= & \int_{\underline{v}}^{\bar{v}} f(v / e)[v-\beta v] d v \\
& -\lambda\left\{\bar{U}-\int_{\underline{v}}^{\bar{v}} f(v / e)[u(v)-\gamma G\{[v-\beta v]-\beta v\}] d v+c(e)\right\} \\
& -\eta\left\{0-\int_{\underline{v}}^{\bar{v}} f(v / e)[u(\beta v)-\gamma G\{[v-\beta v]-\beta v\}] d v+c^{\prime}(e)\right\}
\end{aligned}
$$

The optimal acquisition of shares proportion first-order condition could be obtained and simplified as:

$$
\frac{\partial L}{\partial \beta}=\left[\lambda+\eta \frac{f_{e}(v / e)}{f(v / e)}\right]\left[u^{\prime}(\beta v)+2 \gamma G^{\prime}(v-2 \beta v)\right]-1=0
$$

Take derivatives the output $\mathrm{v}$ of the equation and the optimal condition could be: 


$$
\begin{aligned}
& \eta\left(\frac{f_{e}(v / e)}{f(v / e)}\right)^{\prime}\left[u^{\prime}(\beta v)+2 \gamma G^{\prime}(v-2 \beta v)\right]+\left[\lambda+\eta \frac{f_{e}(v / e)}{f(v / e)}\right] \\
& \cdot\left[\beta u^{\prime \prime}(\beta v)+2 \gamma G^{\prime \prime}(v-2 \beta v)(1-2 \beta)\right]=0 \\
& \eta\left(\frac{f_{e}(v / e)}{f(v / e)}\right)^{\prime}\left[u^{\prime}(\beta v)+2 \gamma G^{\prime}(v-2 \beta v)\right]+\left[\lambda+\eta \frac{f_{e}(v / e)}{f(v / e)}\right](16) \\
& \bullet\left[\beta u^{\prime \prime}(\beta v)+2 \gamma G^{\prime \prime}(v-2 \beta v)(1-2 \beta)\right]=0
\end{aligned}
$$

When the management is risk-neutral, $u^{\prime}(\beta v)=u$, $u^{\prime \prime}(\beta v)=0$, the optimal acquisition of shares proportion first-order condition could be:

$$
\beta=\frac{2 \gamma G^{\prime \prime}(v-2 \beta v)+\frac{\eta\left(\frac{f_{e}(v / e)}{f(v / e)}\right)^{\prime}\left[u^{\prime}(\beta v)+2 \gamma G^{\prime}(v-2 \beta v)\right]}{\left[\lambda+\eta \frac{f_{e}(v / e)}{f(v / e)}\right]}}{4 \gamma G^{\prime \prime}(v-2 \beta v)}
$$

From equation (17), when the management is risk-neutral and the effort level could be contracted, the proportion of equity acquisition is a decreasing function of inequality aversion, which means those management who show inequality aversion do not want to buy more shares, because the relevance among the enhancement of enterprise's performance, the effort of the management layer and their own ability is uncertain and questioned in the existing economic system and external environment. In this case, fairness preference has crowding-out effects on equity incentive contracts. At the same time, the psychological effect corrects the management utility function, which would also influence the game of owner and the management buy-out agreement process.

According to the conclusion above, when the owner (usually government) makes the unreasonable price of the target enterprise, the adverse results would be produced as follows. Setting extravagant price would be considered as threaten to heterogeneity human capital in investment, causing adverse unfair psychological disutility. When the price is too low, the MBO would be prevented seeing that it is regarded as the loss of state-assets. As a result, the management could not be the owner of enterprise, and state-owned enterprise system reform could not realize incentive compatibility, corporate agency cost would increase and social and psychological utility management would be reduced.

\section{MBO GAME EQUILIBRIUM}

\subsection{Process Description of Game Pricing}

In order to get the MBO game equilibrium, given that all bodies are rational and wouldn't make mistakes, here is the description of the game payoffs, utility function types of strategies and game's regulations.

1. Pricing of MBO should be no less than target company's present value of net assets, and not higher than the sum of present value of net assets of the target company, the option value and other values. The game value of MBO, consequently, should be the sum of the present value of net assets (appraised value) and the option value, i.e. $(\mathrm{V}+\mathrm{P})$. However, because of the multi-stage of merge's decision, especially in China's existing economic system, there are many institutional constraints of MBO. Meanwhile, the negotiation process is affected by game subjects, which leads to the wastage of the option value. The coefficient of option value wastage is $\omega$, in that the game value should be $(V+\omega P)$, and assuming it is an effective market of control right with no other costs.

2. MBO decision choice is aiming at utility. In consideration of the management's fairness preferences, MBO decision is a kind of strategic interaction of mental game, and the individual utility function depends not only on the individual choice but also other people's choice. The individual utility function is no longer a function of individual absolute income, but relative income. The utility function of manage-

ment decisions should be $u(\beta v)-\gamma G\{[v-\beta v]-\beta v\}$, and it means that the psychological utility loss caused by acquisition of an inappropriate proportion must be considered. At the same time, decision changes after considering the psychological effects from the correction of fairness preference to the utility function.

3. In a MBO game, there are two types of management with fairness preference. One is cheating type $F$, which conceals assets, transfers profits by taking advantage of information. The other is non cheating type $\mathrm{T}$, i.e. the type space $\theta \in(F, T)$. Cheating leads to the loss of present value $V_{F}$ of enterprise, and value ratio $\kappa$ is presented by irrecoverable enterprises from management cheating. The management with fairness preference has an advantage in information of their own type, and quotation type is divided into high price $P_{h}$ and low price $P_{l}$, i.e. quotation space $P \in\left(P_{h}, P_{l}\right)$. In non cheating type, the conditional probability are:

$$
p\left(P_{h} \mid T\right)=\vartheta_{1} \text { and } p\left(P_{h} \mid F\right)=1-\vartheta_{1}
$$

When cheating is existed, the conditional probability are:

$$
p\left(P_{l} \mid T\right)=\vartheta_{2} \text { and } p\left(P_{l} \mid F\right)=1-\vartheta_{2}
$$

4. Not knowing the specific type of the management, the shareholders have Information disadvantage in MBO. However, they are aware of the prior probability of management with fairness preferences, which are $p(T)=\eta$ and $p(F)=1-\eta$ both on the condition of cheating and not cheating respectively. The action set of owners selection strategy is $a \in\left(a_{1}, a_{2}\right)$, and $a_{1}, a_{2}$ are acquired and not to be acquired respectively.

5. Taking the quote of the management with fairness preference as incentive contract, by using Bayes rule to deduce Posterior conditional probability distribution of the 
management with fairness preference and to judge the real value of enterprises to choose action strategy according to quotes. The marginal probability of high price and low price quoted by management with fairness preference could be:

$$
\begin{aligned}
p\left(P_{h}\right)= & p\left(P_{h} \mid F\right) * P(F)+p\left(P_{h} \mid T\right) * P(T) \\
& =\left(1-\vartheta_{1}\right)(1-\eta)+\vartheta_{1} \eta \\
p\left(P_{l}\right)= & p\left(P_{l} \mid F\right) * P(F)+p\left(P_{l} \mid T\right) * P(T) \\
& =\left(1-\vartheta_{2}\right)(1-\eta)+\vartheta_{2} \eta
\end{aligned}
$$

So we could get the posterior conditional probabilities of quoting high price and low price:

$$
\begin{aligned}
p\left(F \mid P_{h}\right) & =p\left(P_{h} \mid F\right) * P(F) / p\left(P_{h}\right) \\
& =\left(1-\vartheta_{1}\right)(1-\eta) /\left[\left(1-\vartheta_{1}\right)(1-\eta)+\vartheta_{1} \eta\right]=\alpha \\
p\left(T \mid P_{h}\right) & =p\left(P_{h} \mid T\right) * P(T) / p\left(P_{h}\right) \\
& =\vartheta_{1} \eta /\left[\left(1-\vartheta_{1}\right)(1-\eta)+\vartheta_{1} \eta\right]=1-\alpha \\
p\left(F \mid P_{l}\right) & =p\left(P_{l} \mid F\right) * P(F) / p\left(P_{l}\right) \\
& =\left(1-\vartheta_{2}\right)(1-\eta) /\left[\left(1-\vartheta_{2}\right)(1-\eta)+\vartheta_{2} \eta\right]=\alpha_{1} \\
p\left(T \mid P_{l}\right) & =p\left(P_{l} \mid T\right) * P(T) / p\left(P_{l}\right) \\
& =\vartheta_{2} \eta /\left[\left(1-\vartheta_{2}\right)(1-\eta)+\vartheta_{2} \eta\right]=1-\alpha_{1}
\end{aligned}
$$

6. According to dynamic game rules, under the condition of risk-neutral and no conspiracy between original shareholders and the management, the utility function of the subject in each stage could be:

(1) When management is the cheating type and offers high price, and the original shareholders are willing to sell stock right, the utility functions of original shareholders and management are:

$$
\begin{gathered}
U_{F h 1 P}=P_{h}-V-\omega P-V_{F}, \\
U_{F h 1 a}=(1+2 \gamma)\left(V+\omega P+V_{F}-P_{h}\right)
\end{gathered}
$$

(2) When management is the cheating type and offers high price, and the original shareholders are unwilling to sell stock right, the utility functions of original shareholders and management are:

$$
U_{F h 2 P}=-\kappa V_{F}, U_{F h 2 a}=\kappa V_{F}
$$

(3) When management is the cheating type and offers low price, and the original shareholders are willing to sell stock right, the utility functions of original shareholders and management are:

$$
\begin{gathered}
U_{F l 1 P}=P_{l}-V-V_{F}-\omega P, \\
U_{F l 1 a}=(1+2 \gamma)\left(V+\omega P+V_{F}-P_{l}\right)
\end{gathered}
$$

(4) When management is the cheating type and offers low price, and the original shareholders are unwilling to sell stock right, the utility functions of original shareholders and management are:

$$
U_{F l 2 P}=-\kappa V_{F}, U_{F l 2 a}=\kappa V_{F}
$$

(5) When management is the non cheating type and offers high price, and the original shareholders are willing to sell stock right, the utility functions of original shareholders and management are:

$U_{\text {mlP }}=P_{h}-V-\omega P, \quad U_{\text {mla }}=(1+2 \gamma)\left(V+\omega P-P_{h}\right)$

(6) When management is the non cheating type and offers high price, and the original shareholders are unwilling to sell stock right, the utility functions of original shareholders and management are:

$$
U_{T m 2 P}=0, U_{T h 2 a}=0
$$

(7) When management is the non cheating type and offers low price, and the original shareholders are willing to sell stock right, the utility functions of original shareholders and management are:

$$
U_{m P}=P_{l}-V-\omega P, \quad U_{m a}=(1+2 \gamma)\left(V+\omega P-P_{l}\right)
$$

(8) When management is the non cheating type and offers low price, and the original shareholders are unwilling to sell stock right, the utility functions of original shareholders and management are:

$$
U_{T l 2 P}=0, U_{T l 2 a}=0
$$

Specific game structure is shown in Fig. (1): Framework agreement in pricing of shareholders and the management based on behavioral option game.

\subsection{MBO Pricing Equilibrium on Behavioral Option Game}

Owing to the rationality of the original shareholders and management, management with fairness preference would respond to the price signal offered by original shareholders reflecting based on their common belief to make optimal bidding signal to maximize their utility. As a result, MBO pricing equilibrium is to solve the optimal bidding problem, namely the actual equilibrium price of MBO. The specific refining Bias equilibrium could be:

1. Management with fairness preference offers high price $P_{h}$, and the original shareholders of target enterprise choose

to transfer the share ${ }^{a_{1}}$, so the expected utility of original shareholders in target enterprise could be:

$$
U_{h 1 p}^{*}=\alpha \bullet\left(P_{h}-V-\omega P-V_{F}\right)+(1-\alpha) \bullet\left(P_{h}-V-\omega P\right)
$$

If the original shareholders do not choose to sell shares $a_{2}$, then the expected utility of original shareholders in target enterprise could be:

$$
U_{h 2 p}^{*}=p\left(F \mid P_{h}\right) \bullet U_{F h 2 P}+p\left(T \mid P_{h}\right) \bullet U_{T h 2 P}=\alpha \bullet\left(-\kappa V_{F}\right)
$$

Management of hidden action offers high prices, and then the shareholders of the target company choose Bayes mixed strategy 1 under the following condition: 


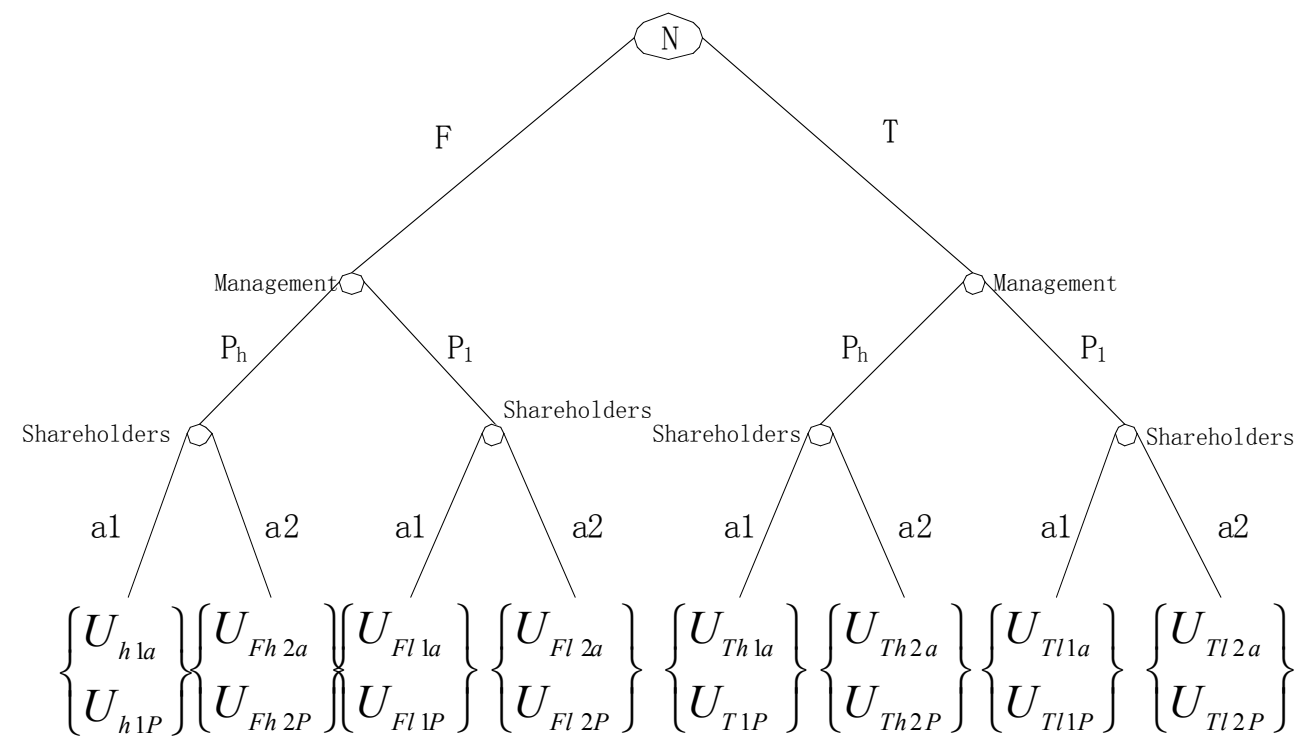

Fig. (1). Framework agreement on pricing of shareholders and the management based on behavioral option game.

$U_{h 1 p}^{*}>U_{h 2 p}^{*}$, i.e. $\alpha<\frac{\left(P_{h}-V-\omega P\right)}{(1-\kappa) V_{F}}$

From equation (18), management buy-out succeeded if management with fairness preference offers high price and the original shareholders accept the transfer of shares. From the above conditions, we could imply that the greater the value of the option, the smaller the critical probability of management buy-out success, namely the posteriori probability of the original shareholders to the management could be smaller. So the option value would take the role of information transmission in the decision-making of $\mathrm{MBO}$, and specific path of information transmission could be analyzed after put into equation (13) so as to make the game pricing closer to the Pareto efficiency. If the MBO related system is imperfect, the institutional cost of negotiation would swallow up the option value, weakening the impact of option value exerted on information transfer function. It is similar to the management with fairness preference offering low prices.

2. Management with fairness preference offers low price $P_{l}$, and the original shareholders of target enterprise choose

to transfer the share ${ }^{a_{1}}$, so the expected utility of target company's original shareholders could be:

$$
\begin{aligned}
U_{l 1 p}^{*} & =p\left(F \mid P_{l}\right) \bullet U_{F l 1 P}+p\left(T \mid P_{l}\right) \bullet U_{T l 1 P} \\
& =\alpha_{1} \bullet\left(P_{l}-V-V_{F}-\omega P\right)+\left(1-\alpha_{1}\right) \bullet\left(P_{l}-V-\omega P\right)
\end{aligned}
$$

If the original shareholders do not choose to sell shares $a_{1}$, then the expected utility of target company's original shareholders could be:

$$
U_{l 2 p}^{*}=p\left(F \mid P_{l}\right) \bullet U_{F l 2 P}+p\left(T \mid P_{l}\right) \bullet U_{T l 2 P}=\alpha_{1}\left(-\kappa V_{F}\right)
$$

Management of hidden action offers low prices, and then the shareholders of the target company choose Bayes mixed strategy 1 under the following condition:
$U_{l 1 p}^{*}>U_{l 2 p}^{*}$, i.e. $\alpha_{1}<\frac{\left(P_{l}-V-\omega P\right)}{(1-\kappa) V_{F}}$

The Bayes mixed strategy equilibrium Equation (19) is the same as Equation (18), and option value is the signal mechanism of Bayes mixed strategy's trigger point.

3. Strategy choice of target company management with fairness preference

(I) From equation (18) and equation (19), the expected utility at high and low prices of the management with fairness preference of target enterprise when cheating could be:

$$
\begin{aligned}
U_{F h 1 a}^{*} & =p\left(\alpha<\frac{\left(P_{h}-V-\omega P\right)}{(1-\kappa) V_{F}}\right) \bullet\left[(1+2 \gamma)\left(V+\omega P+V_{F}-P_{h}\right)\right] \\
+ & {\left[1-p\left(\alpha<\frac{\left(P_{h}-V-\omega P\right)}{(1-\kappa) V_{F}}\right)\right] \bullet\left[\kappa V_{F}\right] } \\
U_{F l 1 a}^{*} & =p\left(\alpha_{1}<\frac{\left(P_{l}-V-\omega P\right)}{(1-\kappa) V_{F}}\right) \bullet\left[(1+2 \gamma)\left(V+\omega P+V_{F}-P_{l}\right)\right] \\
+ & {\left[1-p\left(\alpha_{1}<\frac{\left(P_{l}-V-\omega P\right)}{(1-\kappa) V_{F}}\right)\right] \bullet\left[\kappa V_{F}\right] }
\end{aligned}
$$

(II) From equation (18) and equation (19), the expected utility at high and low prices of the management with fairness preference of target enterprise when cheating could be:

$$
\begin{aligned}
& U_{T h 1 a}^{*}=p\left(\alpha<\frac{\left(P_{h}-V-\omega P\right)}{(1-\kappa) V_{F}}\right) \cdot\left[(1+2 \gamma)\left(V+\omega P-P_{h}\right)\right](22) \\
& U_{T l 1 a}^{*}=p\left(\alpha_{1}<\frac{\left(P_{l}-V-\omega P\right)}{(1-\kappa) V_{F}}\right) \bullet\left[(1+2 \gamma)\left(V+\omega P-P_{l}\right)\right](23)
\end{aligned}
$$

From equation (20) to equation (23), we could see that the strategy of high or low price chosen by the management 
with fairness preference is associated with several factors besides the posterior probability which original owners select to sell. Firstly, option value. Through the influence on posterior probability of original shareholders choosing to sell, the option value has an influence on the management's selection strategy. Secondly, the degree of perfection of control right market. If the control right market is not perfect, the costs of design for the system have a greater loss of option value, thereby reducing the influence of option value on posterior probability. Finally, strategy for selection is also affected by the degree of management's inequity aversion. According to equation (17), the managers of unfair aversion in any kind of strategy conditions would have a negative effect, after subtraction of equation (20) and equation (22) and subtraction of equation (21) and equation (23), we could get that unfair aversion increases the differential utility of cheating and non cheating, namely higher probability of cheating and moral hazard by management with higher degree of inequity aversion, so as to enhance their utility. From the perspective of behavioral option game theory constructed in this paper, psychological disutility produced by fairness preference have a crowding-out effect on managerial ownership's incentive contracts, thereby reducing the incentive effect of managerial ownership.

\section{CONCLUSION}

This paper brings options value generated by uncertainty and psychological effect generated by fairness preference into MBO principal-agent decision-making analysis framework with asymmetric information, to construct behavioral option game analysis framework with management decisionmaking optimization implied with option value and psychological utility. The following conclusions are obtained from the frame. First, the signal display principle of option value is found, and that is to say the change of option value will affect the critical probability of MBO's game equilibrium. Here is the specific conclusions in this paper, that the greater the value of the option, the smaller the critical probability of management buy-out success, namely smaller posteriori probability of the original shareholders to the management. However, if the management's related system of buy-out is imperfect, the system cost of negotiation swallows up the option value, resulting in weakened option value's impact on information transfer. Second, MBO share is affected by inequity aversion. In order to enhance utility, management with higher degree of inequity aversion would increase the probability of cheating and moral hazard. The reason is that psychological disutility produced by fairness preference has a crowding-out effect on managerial ownership's incentive contracts, thereby reducing the incentive effect of managerial ownership. In the research of MBO Pricing mechanism, we must use behavioral option game to assess the value of the target company properly, strengthen the role of option value's signal display in the decision-making process, and design equity incentive contracts which cannot extrude fairness preference, and reduce the moral risk in the management decision-making process.

There are still many issues worth exploring about the behavioral option game model in this paper. Firstly, programs have various types of options and each option has their own particularity. The particularity impacts the fairness preference's heterogeneity and stability, thus affecting the difference of MBO decision-making behavior. Secondly, there is a problem in the relevance of management fairness preference and risk preference. The relevance between risk aversion and social preference was found in experimental study of social preference (Christian\& Schmidt [18]). In the model of MBO principal-agent decision-making with risk aversion, risk aversion would affect utility in the process of certainty method of equivalents. In the model of MBO principal-agent decision-making with fairness preference, fairness preference is directly utilized in the utility function, and these two kinds of psychological preferences would generate repetitive impacts on the utility function, thus leading to the complexity of option game model construction based on the assumption of the management with risk aversion. These questions are the future research priorities.

\section{CONFLICT OF INTEREST}

The authors confirm that this article content has no conflict of interest.

\section{ACKNOWLEDGEMENTS}

Declared none.

\section{REFERENCES}

[1] W. Wang, and X. Jin, "Management Buyouts with Distorted Motivation: A New Explanation to SOEs. Performance Deterioration,' Economic Research, no. 3, pp. 82-89, 2006.

[2] A. Ziegler, "A game theory analysis of options - contributions to the theory of financial intermediation in continuous time", Springer-Verlag, New York, USA, 1999.

[3] F. Smets, "Exporting versus FDI: The Effect of Uncertainty, Irreversibilities and Strategic Interactions," Working Paper, Yale University, 1991

[4] A. K. Dixit, and S. Robert, "Pindyck, Investment under Uncertainty," Princeton University Press, 1994.

[5] H. T.J. Smit, and L.A. Ankum, "A Real Options and GameTheoretic Approach to Corporate Investment Strategy under Competition, " Financial Management, vol. 22, no. 3, pp. 241-250, 1993.

[6] H. T.J. Smit, and L.Trigeorgis, "R\&D Option Strategies," Working Paper, University of Chicago, 1997.

[7] J. Imai, and T. Watanabe, "A Two-stage Investment Game in Real Option Analysis," Discussion Paper, Tokyo Metropolitan University, Paper presented at the 8th annual conference on Real Options Theory, 2004.

[8] J. Imai, and W. Takahiro, "A Numerical Approach for Real Option Values and Equilibrium Strategies in a Duopoly," Paper presented at the 10th annual conference on Real Options Theory, 2006.

[9] Q. Zhang, and Z. Tian, "The Strategic Analysis Framework for Project Investment Portfolio Based on Real Option," Chinese Journal of Management Science, vol. 12, no. 3, pp. 18-21, 2004.

[10] J. Zhou, and D. Huang, "Investment decision behavior on project with expand option," Journal of Management Sciences, vol. 9, no. 2, pp. 28-35, 2006.

[11] X. Wang, and S. Zhang, "Option games in finite investment project life," Systems Engineering-Theory \& Practice, no. 2, 2011.

[12] Y. Huang, "Optimal Timing and Equilibrium Price for Control Rights Transfer of the Company with Debt," Chinese Journal of Management Science, vol. 20, no. 5, pp. 178-184, 2012.

[13] M. Rabin, "Incorporating Fairness into Game Theory and Economics," American Economic Review, vol. 83, pp. 1281-1302, 1993.

[14] M. Dufwenberg, and G. Kirchsteiger, "A Theory of Sequential Reciprocity," Games and Economic Behavior, vol. 47, pp. 268-298, 2004.

[15] A. Falk, and F. Urs, "A Theory of Reciprocity," Games and Eco- 
nomic Behavior, vol. 54, pp. 293-315, 2006.

[16] E. Fehr, and K. M. Schmidt, "A Theory of Fairness, Competition and Cooperation," Quarterly Journal of Economics, vol. 114, no. 3, pp. 817-868, 1999.

[17] G. E. Bolton, and A. Ockenfels. ERC, "A Theory of Equity, Reciprocity, and Competition," American Economic Review, vol. rocity, and Competition," American Economic Review, vol. 90, pp. 166-193, 2000.

[18] S. Traub, C. Seidl, and U. Schmidt, "An experimental study on individual choice, social welfare, and social preferences, "European Economic Review, vol. 53, pp. 385-400, 2009.

(C) Chuan Liu; Licensee Bentham Open

This is an open access article licensed under the terms of the (https:/creativecommons.org/licenses/by/4.0/legalcode ), which permits unrestricted, noncommercial use, distribution and reproduction in any medium, provided the work is properly cited. 